\title{
Methyl Chloride via Oxyhydrochlorination of Methane: A Building Block for Chemicals and Fuels from Natural Gas
}

\author{
Quarterly Technical Progress Report No. 01
}

For the Reporting Period: 30 September 1996 - 31 December 1996

Prepared for the

U.S. Department of Energy

Pittsburgh Energy Technology Center

DoE Award Number: DE-FC22-96PC96050

Date of Issue: 16 January 1997

Principle Author: Jon Wineland

Name and Address of Submitting Organization:

Dow Coming Corporation
4770 U.S. Highway 42 East

Carrollton, KY 41008 


\section{DISCLADMER}

Portions of this document may be illegible in electronic image products. Images are produced from the best available original document. 


\title{
Disclaimer
}

This report was prepared as an account of work sponsored by an agency of the United States Government. Neither the United States Government nor any agency thereof, nor any of their employees, makes any warranty, express or implied, or assumes any legal liability or responsibility for the accuracy, completeness, or usefulness of any information, apparatus, product, or process disclosed, or represents that its use would not infringe privately owned rights. Reference herein to any specific commercial product, process, or service by trade name, trademark, manufacturer, or otherwise does not necessarily constitute or imply its endorsement, recommendation, or favoring by the United States Government or any agency thereof. The views and opinions of authors expressed herein do not necessarily state or reflect those of the United States Government or any agency thereof.

\begin{abstract}
The objectives of this cooperative agreement are to develop the oxyhydrochlorination $(\mathrm{OHC})$ process for the conversion of methane to methyl chloride. In the first Phase of the project, Dow Corning has developed a stable selective catalyst and demonstrated the technology on a laboratory and a pilot plant scale. The current effort builds on earlier learning to pilot the technology on an engineering scale, integrated operation, and to obtain design, scale-up, and cost data for a commercial-scaleprocess economic evaluation Specific tasks to achieve these objectives have been developed as follows:

TASK 1 Fundamental Technical and Economic Evaluation

TASK 2 Catalyst Selection Optimization and Characterization Studies

TASK 3 Pilot Plant Design

TASK $4 \quad$ Pilot Plant Detailed Engineering, Procurement and Construction

TASK $5 \quad$ Pilot Plant Startup and Operation

TASK $6 \quad$ Pilot Plant Process Optimization

TASK 7 Pilot Plant Extended Operation

TASK $8 \quad$ Pilot Plant Economic Evaluation/Scale-up Decision
\end{abstract}

Significant progress has been completed in Task 1 with the objective to complete a fundamental technical and economic evaluation of learning gathered the Phase $J$ effort of this project. A decision to proceed with the project will be made after completion of this Task.

A computer model of the reactor system has been developed, which includes heat and mass transfer effects as well as reactions. Model validation is in progress.

The Absorber/Stripper technology evaluated and implemented on the Phase I PDU to recover chlorocarbons (including methyl chloride) from reaction products has been scaled to evaluate economics for a commercial scale plant. In a parallel exercise, alternate recovery technologies were investigated for economic evaluation, to assure that the minimum capital option is pursued for the Phase Il design.

Commercial scale plant equipment and total plant costs are being evaluated using information from the Phase I PDU, reactor modeling and recovery system evaluation to estimate capital and operating costs for a commercial scale $\mathrm{OHC}$ unit. 


\section{Table of Contents}

$\begin{array}{lr}\text { Executive Summary } & 4 \\ \text { Introduction } & 4 \\ \text { Results and Discussion } & 5 \\ \text { Data Reduction, Interpretation, and Analysis } & 9 \\ \text { Conclusions } & 9 \\ \text { List of Acronyms and Abbreviations } & 9\end{array}$

\section{List of Graphical Materials}

$\mathrm{MeCl}$ Production Cost Savings based on Historical Price DIFFERENCE between $\mathrm{MeOH}$ and $\mathrm{CH} 4$

Extra Capital Justified by Raw Materials Savings

\section{List of Tables}

Table 1: Example Model and Pilot Plant Results 


\section{Executive Summary}

Dow Corning has been conducting research on methods for producing methyl chloride from methane under a cooperative agreement with the U.S. Department of Energy, the Gas Research Institute and the Texas Gas Transmission Company.

In Phase I of this effort, Dow Corning developed a stable selective heterogeneous catalyst and demonstrated the technology on a laboratory scale. A pilot plant was constructed and operated and methyl chloride was produced at about $1 \mathrm{~kg} / \mathrm{hr}(2 \mathrm{lb} / \mathrm{hr})$ scale. However, significant technical challenges, including materials of construction, product recovery, reactor performance and reactor temperature control were encountered.

Phase II of the effort is also supported by a cooperative agreement with the US DoE and with GRI. Following a critical evaluation of the technology, design, construction and operation of an integrated engineering-scale pilot facility will build on the current development and gather sufficient engineering information to design and build a commercial scale plant. The Phase l pilot demonstration included only the reaction and the first two separation steps of the process. The Phase II pilot plant will have a design rate of approximately $450 \mathrm{~kg} / \mathrm{hr}(1000 \mathrm{Jb} / \mathrm{hr})$ and will include steps to separate, recycle and purify final products.

Phase II has begun with a thorough evaluation of the Phase I technology development to date--including the current understanding of technical risks, feasibility and economics--to make a go/no-go decision to proceed with Phase II. This work has commenced and is expected to be complete by May 1997.

\section{Introduction}

Dow Corning has been conducting research on alternate methods for producing methyl chloride since 1982. Methyl chloride $\left(\mathrm{CH}_{3} \mathrm{Cl}\right.$, or $\left.\mathrm{MeCl}\right)$ is used as an intermediate material in silicones production and Dow Corning is the world's largest producer of both. Current technology involves reaction of methanol $\left(\mathrm{CH}_{3} \mathrm{OH}\right.$, or $\left.\mathrm{MeOH}\right)$ with $\mathrm{HCl}$ to produce $\mathrm{CH}_{3} \mathrm{Cl}$ and water:

$$
\mathrm{CH}_{3} \mathrm{OH}+\mathrm{HCl} \rightarrow->\mathrm{CH}_{3} \mathrm{Cl}+\mathrm{H}_{2} \mathrm{O}
$$

Because of methanol's market price volatility, lower cost and more price-stable starting materials are sought for Dow Corning's silicones production. Oxyhydrochlorination (OHC) utilizes methane in a gas phase heterogeneously catalyzed reaction with $\mathrm{HCl}$ and oxygen to produce methyl chloride and water:

$$
\mathrm{CH}_{4}+\mathrm{HCl}+1 / 2 \mathrm{O}_{2} \cdots \mathrm{CH}_{3} \mathrm{Cl}+\mathrm{H}_{2} \mathrm{O}
$$

Similar side reactions occur to convert the $\mathrm{CH}_{3} \mathrm{Cl}$ product to methylene chloride $\left(\mathrm{CH}_{2} \mathrm{Cl}_{2}\right)$, methylene chloride to chloroform $\left(\mathrm{CHCl}_{3}\right)$ and chloroform to carbon tetrachloride $\left(\mathrm{CCl}_{4}\right)$, but these reactions occur to a much lesser extent than the one shown. Another family of side reactions is combustion of these chlorocarbon products to form $\mathrm{CO}$ or $\mathrm{CO}_{2}, \mathrm{H}_{2} \mathrm{O}$ and $\mathrm{HCl}$. Suppression of all of these reactions is desirable to maximize yield of methyl chloride. The combustion reactions are more prevalent at elevated temperatures making reactor temperature control particularly important.

Since methane is approximately half the cost of methanol feedstock on a molar basis, it offers a significant cost advantage, as well as having a more stable market price. Methyl chloride is produced at about 818 million $\mathrm{kg} / \mathrm{yr}$ (1800 million lb/yr) in the USA for many industries including Silicones $(\sim 71 \%)$, Chlorocarbons $(\sim 18 \%)$, Methyl Cellulose $(-4 \%)$, Quaternary Ammonium Salts $(-4 \%)$ and Agricultural Chemicals $(\sim 1 \%)$. 
In addition, methyl chloride and methylene chloride are potential intermediates to produce liquid fuels. Two routes are currently used for liquid fuels production, Methanol-To-Gasoline (MTG) and a FischerTropsch method. However, both begin by reforming methane to synthesis gas $\left(\mathrm{CO}+\mathrm{H}_{2}\right)$, typically over a nickel catalyst, a highly endothermic process. The OHC process can be used to produce methyl chloride and methylene chloride from methane but without the expensive reformation step. These chlorocarbons have been shown to provide reasonable conversions to higher hydrocarbons with minimal carbon deposition on a zeolite catalyst.

United States methanol demand is historically greater than supply, resulting in significant imports. Conversely, methane is relatively abundant (although some is imported). Use of methane instead of methanol for silicones production would significantly reduce the methanol deficit. If the full domestic demand for methyl chloride is considered at 818 million $\mathrm{kg} / \mathrm{yr}$ (1800 million lb/yr, 1995), this requires 647 thousand $\mathrm{m}^{3}$ (171 million gallons) of methanol. If this production were realized from methane instead, it would have cut the 1995 methanol deficit by $14 \%$, or $\$ 100 \mathrm{MM}$ at 16 cents/liter ( 60 cents/gallon). It would also save US industry $\$ 36 \mathrm{MM}$ in raw materials costs.

Dow Corning has been working on a feasibility program to develop $\mathrm{OHC}$ technology using heterogeneous catalysts in a fixed bed reactor. A cost-shared program has been co-funded by Dow Coming, the U.S. Department of Energy (Contract Number AC22-91-PC91030), the Gas Research Institute (GRI Contract Number 5091-222-2300) and the Texas Gas Transmission Company. In this Phase I of the project, Dow Corning has developed a stable selective catalyst and demonstrated the technology on a laboratory and a pilot plant scale. A \$3 MM pilot plant was designed, constructed and operated; materials of construction challenges were overcome and an on-line FTIR analysis of reaction products was developed to measure reactor performance. Methyl chloride was produced in the pilot plant.

While good progress has been made, several technical challenges have been identified, including materials of construction challenges, recovery and separation of products and reactor performance and heat transfer limitations. These issues will be evaluated further and resolved prior to constructing an engineering-scale pilot facility for Phase Il.

\section{Results and Discussion}

Significant progress has been achieved in Task 1 with the objective to complete a fundamental technical and economic evaluation of all information and learning gathered in the design, operation and troubleshooting of the oxyhydrochlorination pilot unit in Phase I. A decision to proceed with the project will be made after completion of this Task.

\section{Subtask 1.1 Reactor}

A spreadsheet computer model of the reactor system has been developed, which includes heat and mass transfer effects as well as reactions. Energy balances are conducted for the catalyst particles and for the bulk fluid phase. Heat generation, conduction and transfer out of the reactor is considered. Chlorination reactions and methyl chloride combustion reactions are included and kinetic effects are included. This work currently requires assumptions of the intrinsic kinetic information which will be subsequently developed in Task 2, but the kinetics are being approximated using laboratory and pilot plant data generated in Phase I. Unfortunately, the data is confounded by poor reactor temperature control, so it is not possible to accurately determine the intrinsic kinetics with this data. However, an example of model output and pilot plant results for a single experimental run is given below to illustrate the potential for the approach. 
Table 1: Example Model and Pilot Plant Results

\begin{tabular}{rccc} 
& \multicolumn{3}{c}{ Model results vs. Pilot Plant } \\
& \multicolumn{3}{c}{ Results } \\
& Actual & Model & $\%$ error \\
$\mathrm{HCl}$ Conversion & $62.4 \%$ & $62.4 \%$ & $0.0 \%$ \\
$\mathrm{CH} 4$ Conversion & $13.8 \%$ & $14.6 \%$ & $5.6 \%$ \\
$\mathrm{CH} 3 \mathrm{Cl}$ Selectivity & $64.0 \%$ & $65.0 \%$ & $1.4 \%$ \\
$\mathrm{CH} 2 \mathrm{Cl} 2$ Selectivity & $14.3 \%$ & $14.4 \%$ & $0.3 \%$ \\
$\mathrm{CO} 2$ Selectivity & $18.5 \%$ & $17.8 \%$ & $-3.3 \%$
\end{tabular}

The model will be used to match data gathered in the PDU to model the temperature profiles and reactor performance observed. The model will allow exploration of reactor conditions which will minimize temperature excursions and temperature gradients which adversely affect performance, and examination of parameters which can improve performance.

\section{Subtask $1.2 \quad$ Recovery System}

The recovery system for the oxyhydrochlorination reactor product must separate chlorocarbon products (chiefly $\mathrm{MeCl}$ ) from unreacted methane and $\mathrm{HCl}, \mathrm{CO}_{2}$ byproducts and generated water. Methane is recycled to the reactor $\left(\mathrm{CO}_{2}\right.$ byproducts are removed as a purge stream), the $\mathrm{HCl}$ and water are a waste stream and the chlorocarbons are separated by distillation. The final distillation of chlorocarbons is very straightforward and not subjected to detailed alternatives investigation, but the reactor product recovery was evaluated.

The Absorber/Stripper technology evaluated and implemented on the Phase I has been scaled to develop economics for a commercial scale plant. In a parallel exercise, alternate technologies are being developed and sized for economic analysis also, to assure that the minimum capital option is pursued in the Phase II design. Materials of construction were considered in this evaluation to minimize costs without introducing undue safety, environmental or operational risks. Recovery system alternatives included direct contact condensation of the reactor products using recycled chlorocarbons (with and without a pre-condenser), distillation, and several options for removing unreacted $\mathrm{HCl}$ prior to all other separation steps to eliminate the downstream requirement for corrosion-resistant materials of construction, as well as pressure-swingabsorbtion (PSA).

Direct contact condensation and distillation options for removing chlorocarbons from the reactor product were determined to be impractical due to the high required flow rate of recycled chlorocarbons for condensation duty, the large size of heat exchangers needed, and the high equilibrium $\mathrm{MeCl}$ concentrations remaining in non-condensed streams. PSA was not pursued due to high costs associated with large equipment size. These evaluations confirm the choice of the absorber/stripper technology made in Phase I. However, removal of $\mathrm{HCl}$ from the reactor product stream was shown to be a useful approach to relax construction materials requirements--and associated equipment costs.

\section{Subtask 1.3 Economic Evaluation}

Commercial scale plant equipment and total plant costs are being evaluated using information from the Phase I PDU, reactor modeling and recovery system evaluation to estimate capital and operating costs for a commercial scale $\mathrm{OHC}$ unit. These costs have been compared with savings realized by utilizing methane in place of methanol as a feedstock to determine if the OHC technology is viable based on projected prices for methane and for methanol. The raw material savings is based on the cost of one mole of methanol versus one mole of methane and one half mole of oxygen (refer to the $\mathrm{OHC}$ reaction in the Introduction). In addition, the conventional technology uses a small amount of $\mathrm{H}_{2} \mathrm{SO}_{4}$ to scrub an impurity from the $\mathrm{MeCl}$ product, while $\mathrm{OHC}$ does not and this generates a small additional savings. 
Historical costs of methanol and methane provide an indication of the magnitude of benefits. As an example, for methanol at $\$ 0.12 /$ iter $(\$ 0.45 / \mathrm{gallon})$, methane at $\$ 108 / 1000 \mathrm{~m}^{3}\left(\$ 3.05 / 1000 \mathrm{ft}^{3}\right)$ and oxygen at $\$ 38.8 / 1000 \mathrm{~m}^{3}\left(\$ 1.10 / 1000 \mathrm{ft}^{3}\right)$ the following savings would be realized:

\begin{tabular}{|c|c|c|c|}
\hline \multicolumn{2}{|c|}{ Conventional Technology } & \multicolumn{2}{|c|}{ OHC Technology } \\
\hline Methanol: & $\$ 2.093 / \mathrm{mole}$ & $\begin{array}{l}\text { Methane: } \\
\text { Oxygen: }\end{array}$ & $\begin{array}{l}\$ 1.026 / \mathrm{mole} \\
\$ 0.197 / \mathrm{h} \text { mole }\end{array}$ \\
\hline TOTAL: & \multicolumn{2}{|c|}{$\$ 2.093 / \mathrm{mole} \mathrm{MeCl}$} & $\$ 1.223 / \mathrm{mole} \mathrm{MeCl}$ \\
\hline
\end{tabular}

Additional operational savings are realized by elimination of the $\mathrm{H}_{2} \mathrm{SO}_{4}$ scrubbing step and additional costs are associated with methane purity requirements, so this difference is adjusted (upward) slightly.

Assumptions: $\quad \mathrm{HCl}$ feeds are not accounted for in this example; it is assumed that the $\mathrm{OHC}$ technology will be optimized to be similarly efficient in $\mathrm{HCl}$ consumption as the conventional process.

The above analyses also assume that unconverted methane (most will be recycled) will be consumed locally as fuel and does not incur a cost penalty to the economics.

Also, byproducts of methylene chloride $\left(\mathrm{CH}_{2} \mathrm{Cl}_{2}\right)$, chloroform $\left(\mathrm{CHCl}_{3}\right)$ and carbon tetrachloride $\left(\mathrm{CCl}_{4}\right)$ are assumed to be sold for further processing by others on an at-cost basis. Dow Corning has identified a potential customer for these materials.

The calculation is repeated using historical methanol and methane prices over the last five years to illustrate the likely magnitude of the savings, as shown in the figure below:

\section{$\mathrm{MeCl}$ Production Cost Savings Based on Historical Price DIFFERENCE Between MeOH and $\mathrm{CH}_{4}$}

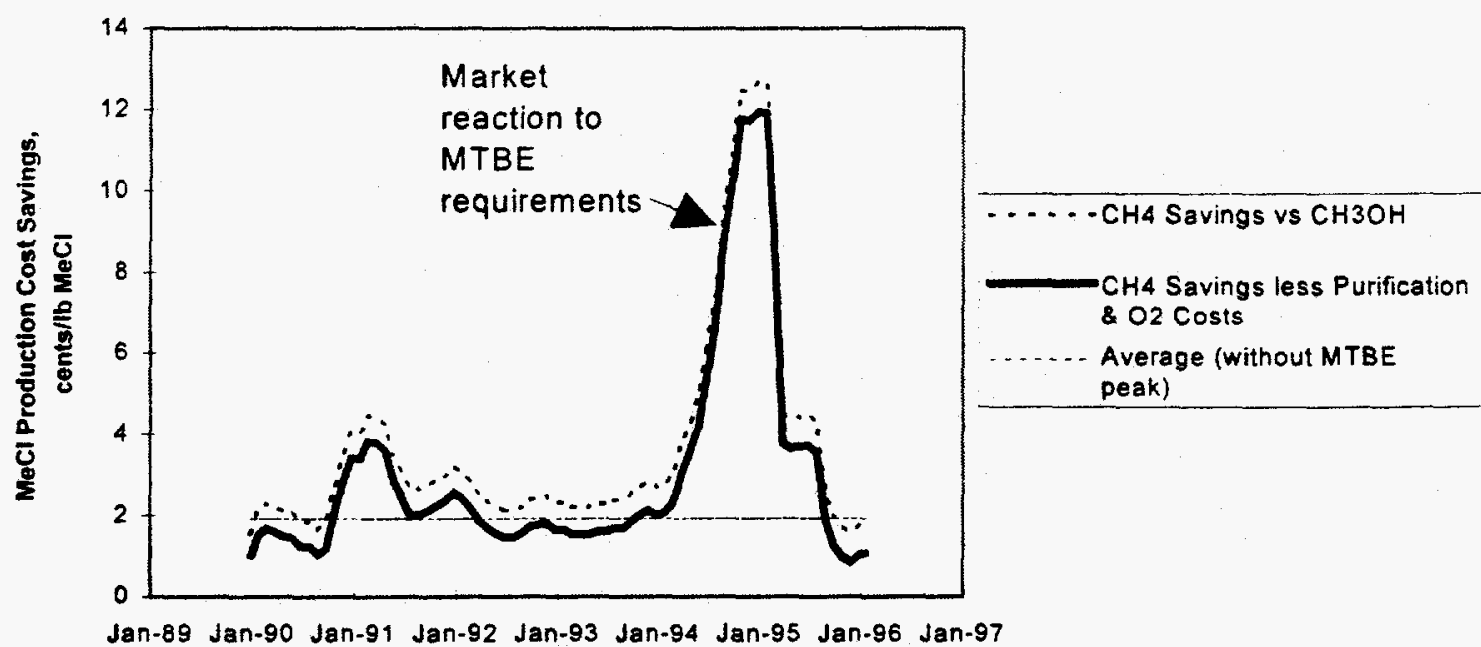

Data sources: $\quad \mathrm{CH}_{3} \mathrm{OH}$ - Chemical Marketing Reporter $\mathrm{CH}_{4}$ - Energy Information Administration, Natural Gas Monthly $\mathrm{O}_{2}, \mathrm{CH}_{4}$ purification and $\mathrm{H}_{2} \mathrm{SO}_{4}$ - commercial quotations 
The sharp peak in the difference is a result of US Clean Air Act Amendments requiring re-formulated gasoline in certain designated areas. This caused the methanol market to react due to increased demand on methyl tert-butyl ether, a gasoline additive produced from methanol. However, producers added excess capacity and the federal government allowed some states to opt out of using reformulated gasoline; the market plummeted. If this peak is ignored, the average savings for methyl chloride using methane instead of methanol is about 4 cents $/ \mathrm{kg}$ ( 2 cents $/ \mathrm{lb}$ ).

Dow Corning recognizes that the OHC technology will be more expensive to design and build than conventional technology for producing methyl chloride using methanol feedstock, owing to process complexity, lower per-pass conversions and challenging materials-of-construction issues. However, the savings highlighted above allow additional capital investment while still achieving an economically advantageous plant.

A simple analysis considers payback of the raw material savings provided by $\mathrm{OHC}$. This savings pays back the extra capital spent in excess of conventional technology. If a five year payback criteria is used-that is: additional capital invested is returned by the savings of five years' operation--the following chart illustrates the additional capital which can be invested on $\mathrm{OHC}$ at various savings rates for $\mathrm{MeCl}$ production:

\section{Extra Capital Expenditure justified by Raw Materials Savings}

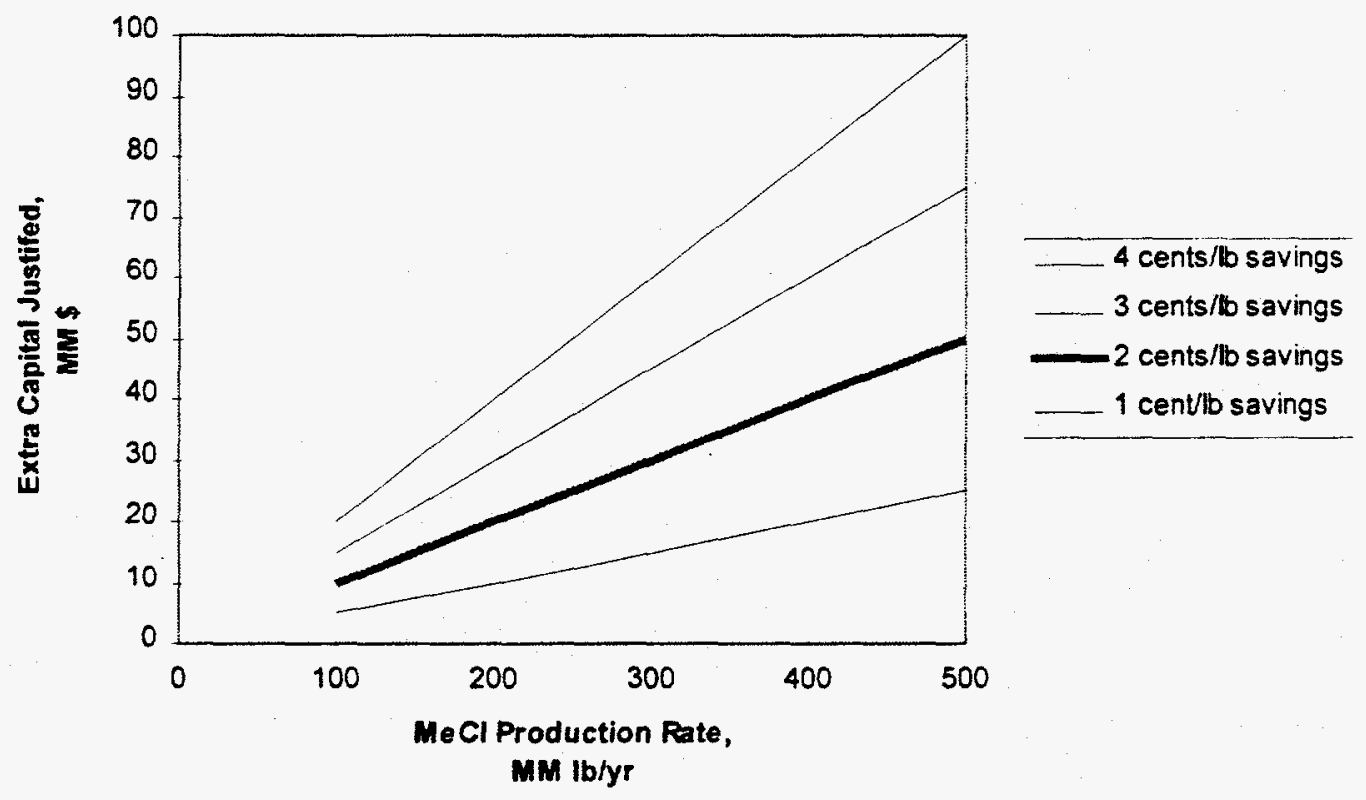

So, conservatively, at 4 cents $/ \mathrm{kg}$ ( 2 cents/lb) savings for $\mathrm{MeCl}$ for a $227 \mathrm{M}$ te/yr ( $500 \mathrm{MM} \mathrm{lb} / \mathrm{yr}$ ) methyl chloride production rate, an $\mathrm{OHC}$ plant can be economically justified at $\$ 50 \mathrm{MM}$ additional capital ABOVE capital costs for the conventional technology.

Dow Corning is currently evaluating the capital costs for the OHC technology, bearing in mind the technical hurdles Phase I work has identified. The major issues are materials of construction challenges, recovery and separation of products and reactor performance and heat transfer.

Any practical alternatives which are identified during the technical and economic evaluation which could increase the chance for a successful technology commercialization without imposing undue risk or 
uncertainty will be considered for replacing the existing technology definition. The DoE Project Officer will review and approve any such changes in use of DoE funds.

A decision to proceed with Phase IJ of the project will be made when these factors are developed and considered by Q2 1997.

\section{Data Reduction, Interpretation, and Analysis}

No experimental data was generated in this Quarter of the Phase Il effort.

\section{Conclusions}

The oxyhydrochlorination reactor can be modeled, but intrinsic kinetic information is needed to realize the full power of this technique. However, it appears that some learning of important reactor parameters needed to optimize performance will be developed in advance of rigorous evaluation of the reaction mechanism.

Recovery system alternative evaluations have confirmed that the absorber/stripper separation technique developed in Phase $I$ is the appropriate choice for removing chlorocarbons from the reactor product, and can be improved by removal of $\mathrm{HCl}$ from the reactor product to allow use of less robust--and less costly-construction materials.

Simple economic evaluation confirms that about $\$ 50 \mathrm{MM}$ extra capital can be spent on a $227 \mathrm{M}$ te/yr (500 $\mathrm{MM} \mathrm{lb} / \mathrm{yr}) \mathrm{MeCl}$ production rate $\mathrm{OHC}$ plant and still achieve acceptable payback through raw material savings in comparison with methanol-based technology. Capital cost estimation on the best achievable design and reactor performance continues to determine if the oxyhydrochlorination technology can be executed within these constraints.

\section{List of Acronyms and Abbreviations}

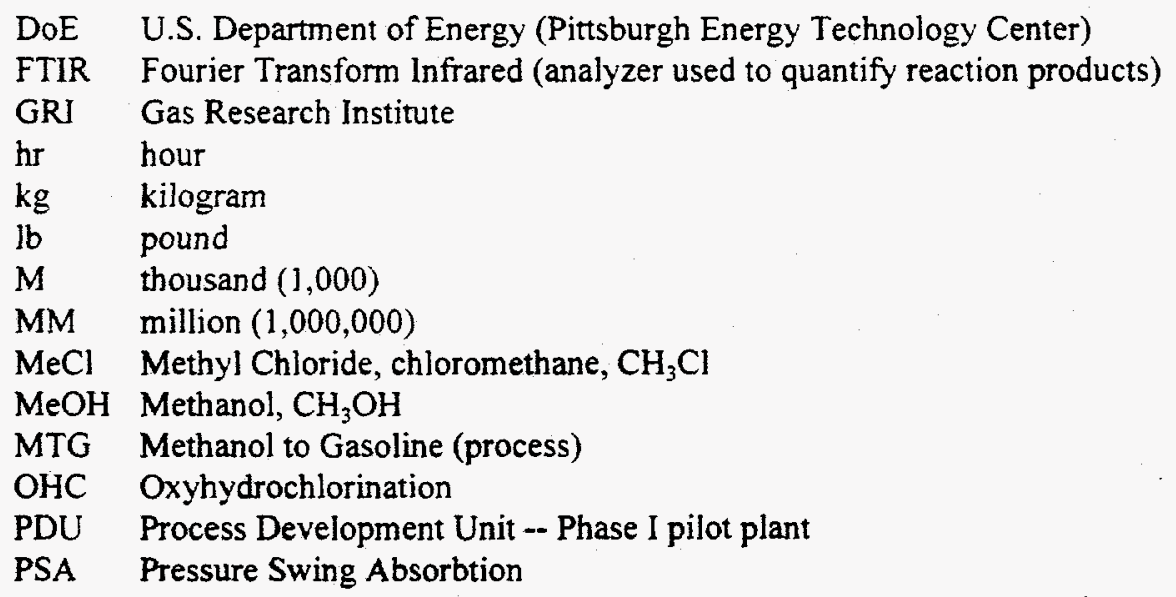

Phase II Technical evaluation, catalyst development, engineering scale demonstration and optimization for commercial scale-up of oxyhydrochlorination to produce methyl chloride from methane.

te tonne, metric ton $(1,000 \mathrm{~kg})$

yr year 